R. J. Cohen and W. T. Sullivan, III, eds.

\title{
Radio Astronomy and the International Telecommunications Regulations
}

\author{
Brian Robinson \\ Research Fellow Emeritus, Australia Telescope National Facility, P.O. \\ Box 76, Epping, NSW 2121, Australia
}

\begin{abstract}
For forty years radio astronomers have had access to frequency bands allocated by the International Telecommunication Union (ITU) - initially a League of Nations body (from 1919) and then a United Nations body (since 1945). Hard work and skilful negotiation by a handful of radio astronomers since 1959 have ensured viable access to scarce spectral allocations. There have been many battles won, some key battles lost. The next treaty conference of the ITU is in the year 2000 .
\end{abstract}

\section{Treaty Conferences}

The ITU holds treaty conferences every few years, with preparatory technical meetings in the years between. The conferences are called World Radio Conferences (WRCs) - originally called World Administrative Radio Conferences (WARCs).

Radio astronomy has argued its case strongly at many World Radio Conferences - in 1959, 1963, 1971, 1979, 1988, 1992 and 1997, for example. Some conferences were not attended - and a high price is still paid for those oversights.

At World Radio Conferences accredited bodies may speak and submit documents. But only governments can vote on matters to be incorporated in the resolutions, which become a treaty document - the Radio Regulations - for each country to sign.

Traditionally the delegates to World Radio Conferences were mainly government representatives, but in the last decade we have seen large numbers of industry representatives on the delegations. At WRC-1997 the U.S. had 99 delegates, Japan 81, France 74 and the U.K. 47; most developing nations could send only two delegates.

Third World countries are worried by the direction the ITU has been taking. They fear that, by the time they get onto their feet, the highly industrialised countries will have the whole radio spectrum exclusively sewn up. They see that the number of cellular phones in industrialised countries has grown from 144 million in 1996 to 274 million in 1998.

The ITU does not regard all services equally - some get PRIMARY allocations. Other services got SECONDARY allocations, meaning that they must not interfere with a Primary service. Lower down the scale of protection are the services who just get in, with FOOTNOTE allocations: they must not interfere with Secondary or Primary services. But "must not interfere" is loosely defined 
- the ITU does not face up to the fact that some services (e.g. passive space research, remote sensing and radio astronomy) work at minuscule signal levels compared to transmissions for broadcasting, mobile communications, radar, etc.

An allocation in an ITU treaty that two services share a band does not guarantee protection for a service using very low signal levels. Furthermore the ITU has been blind to scores of footnotes in the Radio Regulations that state "Emissions from space and airborne stations can be particularly serious sources of interference to the radio astronomy service."

The ITU's engineering arm is ITU-R (long known as CCIR, the Comité Consultatif International des Radiocommunications), which produces "Recommendations" and standards carrying much weight at WRCs. Many ITU-R recommendations specify constraints on sharing between services. However, conclusions of ITU-R are reached by agreement between members of "study groups"; this usually works well, but there have been notorious cases of deliberate disagreement.

\section{Successes}

The efforts of a few dedicated radio astronomers, supported by government delegates from their countries, have achieved many notable successes over the last forty years. A contributory factor was that radio astronomers were usually technically well ahead of the communications industry and working in short wavelength bands that no one else had begun to use.

\subsection{WARC-1959}

Although falling considerably below the hopes of radio astronomers, the 1959 WARC laid a good basis for Radio Astronomy, notably the exclusive "passive" band at $1420 \mathrm{MHz}$ for 21-cm hydrogen line observations. Prior to 1959 the ITU only recognised active radio "services", such as broadcasting, fixed networks, radio navigation, radar, mobile communications, amateur use and meteorological aids. In 1959 there was little commercial or military demand for frequencies above $1000 \mathrm{MHz}$, and allocations (in footnote form) of reasonable bandwidth were possible.

For radio astronomy the main burden at WARC-1959 fell on Charles Seeger (Secretary of URSI Sub-Commission Ve). John Findlay (1988) describes the support of The Netherlands and the United Kingdom in 1959, and the opposition of the United States (see Walter Sullivan (1959), John Lear (1959) and John Finney (1959)).

\subsection{WARC-1963}

During the preparations for WARC-1963, the ITU "formally recognised IUCAF as an active participant in the work of CCIR and the ITU" (Smith-Rose 1961). IUCAF (the Inter-Union Commission on Frequency Allocation for Radio Astronomy and Space Science) had been formed in 1960 to present the frequency allocation requirements of URSI, IAU and COSPAR, the three ICSU unions concerned with space research and radio astronomy. 
The discovery of the main $\mathrm{OH}$ lines at 1665 and $1667 \mathrm{MHz}$ was announced during WARC-1963 and an allocation was made on the spot. The $1612-\mathrm{MHz}$ and $1720-\mathrm{MHz} \mathrm{OH}$ lines were discovered the following year, and footnote allocations were made at WARC-1971.

\subsection{WARC-1971}

At WARC-1971, which allocated frequencies up to $275 \mathrm{GHz}$, the hydrogen line band was extended down to $1400 \mathrm{MHz}$ to cater for redshifts in emissions from more remote sources, and the main $\mathrm{OH}$ lines at 1665 and $1667 \mathrm{MHz}$ received Primary allocation.

The advances in centimetre-wave and millimetre-wave radio astronomy had come along at just the right time - Townes and his collaborators had found ammonia at $23.7 \mathrm{GHz}$ and water vapour at $22.235 \mathrm{GHz}$ in 1968 , while Zuckerman, Palmer, Snyder and Buhl found formaldehyde at $4.829 \mathrm{GHz}$ in 1969 . Then in 1970 Jeffert, Penzias and Wilson discovered the carbon monoxide line at 115.271 $\mathrm{GHz}$.

The richness of the mm-wave spectrum in molecular lines also gave radio astronomy an entree into the top end of the radio spectrum, which other services had not begun to use (Horner 1971). Bands were allocated to ammonia at $23.7 \mathrm{GHz}$ and hydrogen cyanide at 86.3 and $88.6 \mathrm{GHz}$. Footnote allocations were made to hydroxyl (1611.5-1612.5 and $1720-1721 \mathrm{MHz})$, formaldehyde $(4.829$ $\mathrm{GHz})$, excited hydrogen $(5.763 \mathrm{GHz})$, formaldehyde $(14.489 \mathrm{MHz})$, water vapour $(22.235 \mathrm{GHz})$, excited hydrogen $(36.466 \mathrm{GHz})$ and carbon monoxide $(115.271$ $\mathrm{GHz}$ ). The highest radio astronomy allocation was at $240 \mathrm{GHz}$.

On the other hand, WARC-1971 allocated broadcasting satellites the band $2500-2690 \mathrm{MHz}$, immediately adjacent to the $2690-2700 \mathrm{MHz}$ radio astronomy allocation (this is discussed later). And an allocation to an aircraft microwave landing system at $5000 \mathrm{MHz}$ was adjacent to the $4990-5000 \mathrm{MHz}$ radio astronomy band (see later).

Recommendation Spa2-8 from WARC-1971 was entitled "Relating to the Protection of Radio Astronomy Observations on the Shielded Area of the Moon". Arthur C. Clarke (1961) had suggested the lunar shielded area as a location for Radio Astronomy. From 1974 CCIR studied the need to keep the radio spectrum quiet on the far side of the Moon.

\subsection{WARC- 1979}

An enormous international effort went into WARC-1979, the first "WARC General" after 1959, i.e. covering the whole spectrum. This WARC opened up the radio spectrum to $275 \mathrm{GHz}$.

Horner's report (1980) says of radio astronomy and space research:

The overall outcome is widely considered to be satisfactory for these sciences; indeed the general opinion is that they have received very favourable treatment, but some provisos will be mentioned below.

There was a strong and cohesive radio astronomy group ... five (radio astronomers) were involved for various periods as representatives of IUCAF. 
... in the case of radio astronomy there was a significant increase in the number of (frequency) table allocations. ... In space research ... there are considerable gains in allocations for sensing of the Earth's surface and atmosphere by both radiometric and radar techniques.

WARC-1979 allocated Radio Astronomy sixteen bands, between 322-328.6 $\mathrm{MHz}$ and $105-116 \mathrm{GHz}$. Allocations by footnote were made to 18 bands, between $140 \mathrm{GHz}$ and $348 \mathrm{GHz}$. The WARC also approved a Dutch proposal for "Article 36 " in the Radio Regulations, setting out the basic operation and needs of Radio Astronomy. There were also sections on "Radio Astronomy in the Shielded Zone of the Moon" and "The Search for Extraterrestrial Emissions" plus new definitions of interference and "unwanted emissions".

\subsection{WARC-1992}

At WARC-1992 the status of Space Research and Radio Astronomy was significantly enhanced between 137 and $3000 \mathrm{MHz}$, and above $13.5 \mathrm{GHz}$. Delegates from 125 countries clearly recognised the importance of scientific use of the radio spectrum in the face of increasing pressures from telecommunications, broadcasting and navigation interests - particularly where the proposed transmissions were from satellites.

IUCAF delegates became immersed in the projected characteristics of Digital Radio Broadcasting, High Definition TV, the "Big-LEOs" and the "Little LEOs" - the explosion of mobile communications via Low-Earth-Orbit satellites.

\subsection{WRC-1997}

At WRC-1997 a major issue was the allocation of a radar band at $94 \mathrm{GHz}$ for the Earth Exploration Satellite Service (EESS). IUCAF was heavily involved in the placement of this allocation and setting limits on the number of satellites.

\subsection{WRC-2000}

A full report on IUCAF's preparations for WRC-2000 has recently appeared (Baan 1999). An IUCAF-CRAF-CORF position paper is being produced, addressing 12 WRC agenda items - such a High Altitude Platforms at $48 \mathrm{GHz}$, allocations to the Mobile Satellite Service (MSS) and MSS feeder links, ... There is to be an epic review of allocations from 71 - $275 \mathrm{GHz}$ to EES (passive) and Radio Astronomy, with consideration of protection zones around mm-wave observatories.

\subsection{IAU and CCIR Priorities for Radio Spectral Lines}

During the 1970 s there was a flood of discoveries of molecular spectral lines. By 1976, 220 molecular lines were known in the radio spectrum. IAU Commission 40 set up a Working Group (chaired by Brian Robinson) to determine the priorities to be given to the molecular lines during preparations for WARC-1979. By 1979 about 600 molecular lines were known between 0.8 and $346 \mathrm{GHz}$. An IAU list of 30 key spectral line frequencies was agreed to at the 1979 IAU General Assembly in Montreal (Robinson \& Whiteoak 1979, Westerhout 1979). The IAU submitted the list of key spectral lines to CCIR in Geneva, who incorporated it in CCIR 
Recommendation No. 314. CCIR Recommendations carry great weight in the deliberations at a WRC.

The IAU Working Group continued to evaluate the key spectral lines at every IAU General Assembly for the next 21 years. Each time the revisions were adopted by CCIR (now known as ITU-R). This Symposium needs to reactivate the IAU/ITU(R) listing of key spectral lines.

\subsection{Filtering the GMS Meteorological Satellite}

A bright spot in the 1970s was successful negotiations with Japan on the outof-band transmissions from the Geostationary Meteorological Satellite (GMS), which would have extended sidebands to cause harmful interference to radio astronomy observations in the $\mathrm{OH}$ band 1660 to $1670 \mathrm{MHz}$. Effective filtering of widespread unwanted sidebands was shown to be feasible.

During design of the GMS satellite, Brian Robinson (an IUCAF Correspondent) contacted the Japanese Meteorological Agency and encouraged them to build a filter to protect the $\mathrm{OH}$ band. Hughes Aircraft Company engineers said that such a filter could not be built, so the Japanese decided to design and build it. The satellite was launched in 1977. Observations of the GMS satellite are reproduced in Robinson \& Whiteoak (1979). In the radio astronomy band the filter gave 60 decibels attenuation of the GMS sidebands.

\subsection{The Illegality of GLONASS Transmissions}

Prior to WARC-1992, Radio Astronomy use of the most important $1612 \mathrm{MHz}$ satellite line of $\mathrm{OH}$ had been authorised by Footnote $352 \mathrm{~K}$ inserted in the Radio Regulations at WARC-1971. The Footnote warned that "Emissions from space and airborne stations can be particularly serious sources of interference to the radio astronomy service." But, later, WARC-1979 had inserted Footnote 352A reserving the whole band $1610-1626.5 \mathrm{MHz}$ on a worldwide basis for "airborne electronic aids to air navigation and any directly associated ground-based or satellite-borne facilities."

In April 1983 the Soviet Government advised, using the regular ITU "Article 14" coordination procedures, its plan to operate a GLObal NAvigation Satellite System - shortened to GLONASS. Only one country responded to the announcement of this satellite system - but later than the 45-day cut-off for objections. Then radio astronomy observations of the $\mathrm{OH}$ line were closed donw by the horrific interference produced by these GLONASS satellites near $1612 \mathrm{MHz}$. Two "footnote" ITU allocations had equal legal status, and radio astronomers could only lament their oversight.

In May 1991 Russia approached the ITU seeking improved status for GLONASS in the band $1597-1617 \mathrm{MHz}$. This time IUCAF was immediately alert and organised opposition from 10 countries to the Russian request to ITU which then lapsed. IUCAF argued that GLONASS should confine its emissions to the band 1559 to $1610 \mathrm{MHz}$ that had been allocated by WARC-1979 to Radionavigation Satellites and Aeronautical Radionavigation.

IUCAF confronted the Russian Space Forces in Moscow in October 1991. After much negotiation, the Russians undertook to eliminate the out-of-band emissions of the GLONASS system "beginning from 1994 in process of replacement of the Space apparatuses with new ones equipped by improved filters." 
At WARC-1992 the situation changed dramatically, when Radio Astronomy at $1612 \mathrm{MHz}$ gained full Primary status in the band. GLONASS with Footnote status could not interfere with a Primary Service.

In June 1992 IUCAF confronted the Russian Space Forces again in Moscow and arranged that a delegation from the Space Forces and the Institute of Space Device Engineering would visit the Jodrell Bank telescope in November 1992 to witness the interference for themselves. The Russians were amazed at what they saw.

At a further meeting with IUCAF in Moscow (June 1993), the Space Forces recognised the illegality of their transmissions and agreed to move their operating frequencies away from the 1610.6 - $1613.8 \mathrm{MHz}$ Radio Astronomy band. A final agreement with IUCAF was signed in November 1993. All GLONASS satellite transmissions will be out of the band by the year 2007 .

\section{Other Successses}

\subsection{The SSU Series Satellites}

In April 1976 the U.S. launched three "SSU" satellites, which produced strong interference at $1420 \mathrm{MHz}$ - signals a billion times stronger than the interstellar hydrogen emissions. After Canada protested that the signals were in contravention of the ITU allocations (Argyle et al 1977), the data dumps from the satellites ceased while the satellites were over the Pacific Northwest and Canada.

\subsection{Broadcasting Satellites at $22 \mathrm{GHz}$}

In 1991 IUCAF was advised of Japanese plans to license a broadcasting satellite at $22.6 \mathrm{GHz}$ with a bandwidth of $120 \mathrm{MHz}$. The $22.21-22.5 \mathrm{GHz}$ band is a Primary allocation to space research, radio astronomy and earth exploration. Protests were made by eight countries in the Asia-Pacific region. The Japanese proposal failed to gain ITU registration (under "Article 14" procedures).

\section{Failures}

In a number of cases Radio Astronomy has failed to gain ITU allocations or achieve protection from incompatible services.

\subsection{Continuum Bands}

The discoveries of atomic and molecular lines were well timed in terms of the WARC timetable, which gave them plenty of impact. Since the frequencies were fixed and immovable, the allocation had to be just there. But from WARC1959 on, requests were also made by radio astronomers for continuum bands. A bandwidth of $2.5 \%$ was sought in each octave. The requests for continuum bands have, over all the years, got nowhere.

\subsection{INMARSAT Satellites}

At WRC-2000 an old problem will be an extension band desired by INMARSAT around $1660 \mathrm{MHz}$. The IUCAF Report to ICSU in 1992 discussed "sharing prob- 
lems in the band 1660 to $1660.5 \mathrm{MHz}$ and out-of-band interference in the band 1660 to $1670 \mathrm{MHz}$ from aircraft communicating with INMARSAT satellites." The 1992 Report said: "Discussions with INMARSAT on these problems have been unproductive." Nothing has changed!

\subsection{Iridium Satellites}

Did the emptying of the Radio Astronomy band by GLONASS satellites open the door to allow Motorola Iridium satellites to move in?

The struggle about Iridium satellites began in 1991 at CCIR meetings, where the spurious and unwanted emissions from the satellites were ill-defined but threatening. The name Iridium came from the original plan to have 77 LEO satellites; the Iridium nucleus is orbited by 77 electrons. Later Motorola reduced the proposal to 66 satellites, but have not yet renamed the system Dysprosium! The danger posed by Iridium is discussed by Abbott (1996) and Ponsonby (1996). Scientists negotiating with Motorola were surprised by the dictatorial style of the would-be satellite operators - even the Russian Space Forces were more pliable about GLONASS interference!

The U.S. National Radio Astronomy Observatory signed an agreement with Iridium in 1994. All other observatories adopted a strong defensive position behind the IUCAF banner. In 1998 Arecibo Observatory signed a Memorandum of Understanding with Iridium on much better terms than accepted by NRAO. Later in 1998 Australia signed an agreement with Motorola allowing use of Iridium mobile phones subject to "the licensee must not cause harmful interference to Australian radio astronomy services." At this Symposium we have heard of an improved agreement negotiated with Motorola by CRAF on behalf of European countries.

In 1999 the full constellation of Iridium satellites is in orbit, but very high costs to users have greatly inhibited demand. Also, acquiring the satellites has been difficult when users are inside buildings!

\section{Partial Successes}

An ongoing fight has been about ITU Recommendation 66 of WARC-79. Within ITU activities, "Recommendations" are the highest level of directive. Also World Radio Conferences are the highest level of authority. Organs of the ITU like ITU-R must take note of Recommendations, especially if they come from a WARC.

When WARCs allocate frequency bands to different users it is hard to avoid incompatible neighbours. The hyper-sensitivity of radio telescopes to low-level "unwanted", spurious and out-of-band emissions leaves them particularly exposed to these emissions. WARC-1979 issued "Recommendation 66" as a directive to CCIR to carry out studies of the Maximum Permitted Levels of Spurious Emissions "as a matter of urgency".

CCIR did absolutely nothing! The vested interests of the satellite operators made sure nothing happened! Thirteen years later the directive to CCIR to examine spurious and unwanted emissions was renewed by the 1992 WARC. For several years an ITU-R Task Group aimed to produce a set of protection levels that could be approved by WRC-1997. The Task Group could agree 
only on compromise "design objective" levels which were two or three orders of magnitude too high to protect Radio Astronomy.

At WRC-1997 Recommendation 66 was again on the agenda: WRC-1997 recognised the inability of the ITU-R Task Group to propose adequate protection for Radio Astronomy. A new Task Group has therefore been set up, to report to a future WRC. In summary there has been pitifully little progress in the 20 years since Recommendation 66 was first introduced at WARC-1979.

\section{6. "Narrow Squeaks"}

\subsection{The Needles Project}

In 1960 Project WEST FORD - the "Needles Project"- presented a great threat to radio astronomy, optical astronomy and space research, and called for a combined response by URSI, IAU and COSPAR. At that time IUCAF was set up as an ICSU Inter-Union Commission (see Smith-Rose 1960).

Many articles were published to point out the dangerous pollution of space around the Earth by the Needles Project. Anticipating new communications and navigation systems with powerful transmitters in earth satellites, Lilley (1961) concluded: "The pursuit of basic science and the progress of space radio technology represent needs of man which must be advanced. For the impending interference a simple solution exists: allocation of clear frequency bands for basic science. This action is imperative and must ultimately rest on national and international agreements."

The 1961 IAU General Assembly passed a resolution:

... maintaining that no group has the right to change the Earth's environment in any significant way without full international study and agreement;

the International Astronomical Union gives clear warning of the grave moral and material consequences which could stem from a disregard of the future of astronomical progress,

and appeals to all Governments concerned with launching space experiments which could possibly affect astronomical research to consult with the International Astronomical Union before undertaking such experiments and to refrain from launching until it is established beyond doubt that no damage will be done to astronomical research.

Fortunately, the Needles experiment was short-lived and other such experiments have not followed. It is appropriate that IAU Symposium 196 revisit these resolutions made 38 years ago. Many threats now come from commercial projects.

\subsection{ATS-6 at $2700 \mathrm{MHz}$}

After WARC-1971 a broadcasting satellite ATS- 6 was built to operate adjacent to the radio astronomy band at $2700 \mathrm{MHz}$. IUCAF alerted radio astronomers to the danger. A filter was added to the satellite at the last moment to protect the Radio Astronomy band. 


\subsection{Microwave Landing System at $5 \mathbf{G H z}$}

A microwave landing system (MLS) for civil aircraft was proposed to replace the old system at $200 \mathrm{MHz}$. The new MLS system operates at $5 \mathrm{GHz}$, adjacent to the radio astronomy band. By 1999 only five of the MLS systems have been installed at airports. Fortunately, the MLS system has been supplanted by the use of GPS, particularly differential-GPS, as an aircraft landing aid.

\section{Spread Spectrum Modulation}

Many satellite communication or navigation systems use various forms of spreadspectrum modulation. Some basic spread-spectrum systems generate a wide spread of unwanted sidebands, whose intensity falls off very slowly [as the square of $(\sin x) / x$ ] to each side of the central frequency. Examples of satellites causing interference from these unwanted sidebands were the first series of GPS satellites and GLONASS satellites.

The widespread interference can be avoided in well-designed modulation systems. One approach has been suggested by Ponsonby (1991). Also, Delogne \& van Himbeeck (1995) showed that out-of-band radiation can be carefully controlled in well-designed spread-spectrum systems. Direct Sequence Spread Spectrum Modulation can be perfectly confined in a nominal bandwidth of 1.5 times the "chip rate". The contribution of digital signal processing to efficient use of the radio spectrum is discussed further by Delogne and Bellanger (1999).

\section{The Future}

Radio Astronomy has great visions for the 21st Century. Kellerman (1997) has described many of the proposals, and elsewhere in this volume Ron Ekers describe other projects.

But the communications and broadcasting industries also have extensive and ambitious plans that will often compete for the same spectral bands. Over many decades, the ITU's attempts to accommodate incompatible spectral demands has been a succession of poor compromises. Can the ITU do a more competent job in the 21st Century? That seems unlikely now that commercial interests have much more influence on ITU decisions than national governments. The ITU needs to have the foresight to maintain in the radio spectrum the clarity of particular windows on the Universe that mankind needs to enhance and extend our understanding of the evolving Universe about us.

\subsection{Electromagnetic Environmental Impact Statements}

At Lille in 1996, URSI considered interference to radio astronomy from satellites and:

'called on the ITU and affiliated national and regional administrations to encourage the use of modulation schemes that minimise harmful interference, to require pre-flight testing of satellite transmission systems, to devise rulemaking that prevents new users from disrupting existing users, and to require electromagnetic environmental impact statements before operation is authorized. 
This URSI proposal for electromagnetic EIS needs to be discussed at IAU Symposium 196, and considered by IAU at the General Assembly in the year 2000 . We trust that UNESCO will support this proposal.

\subsection{Radio Quiet Reserves}

Butcher (this volume) has discussed the OECD Megascience Forum suggestion of radio-quiet reserves for proposed radio astronomy arrays of very great sensitivity.

Many people at this IAU Symposium were at the 1992 Exposition in Paris, where UNESCO was exploring the possibility of designating a few selected observatories as World Heritage Sites. Has anything yet come of this?

A variation on this approach is suggested by the Antarctic Treaty of 1959, which followed the extensive scientific work carried out in Antarctica during the International Geophysical Year 1957-58. The Treaty has been supplemented by the 1991 Madrid Protocol, with a commitment that Antarctica and its environment is a natural reserve, devoted to peace and science, and stressing cooperation. Mineral resource activity is prohibited. The Antarctic Treaty states that in the interests of mankind, Antarctica should continue forever to be used exclusively for peaceful purposes. Military uses are prohibited. No future actions can be used to support prior national claims, and no new national claims can be made.

Radio-quiet reserves could be protected by a similar treaty, with a guarantee of low levels of interference and exclusion of satellite and airborne emissions.

\subsection{Dedicated Passive Spectrum}

There is another approach: the relentless exploitation of land can be limited by the declaration/consecration of national parks. Could the exclusive "passive" bands required by Radio Astronomy, Space Research and Earth Exploration be kept in a pristine state as "international parks" in the radio spectrum, under the protection of UNESCO? This issue needs to be followed up with IAU, URSI, COSPAR, ICSU and UNESCO.

Acknowledgments. I have received much help in this review from Jim Cohen, Sir Francis Graham-Smith, Fred Horner, Willem Baan, John Whiteoak and Emile Blum. I have also received strong support from the IAU Secretariat, the URSI Secretariat and ICSU.

\section{References}

Abbott A. 1996, Nature, 380, 569

Argyle E., Costain C. H., Dewdney P. E., Galt J. A., Landecker T. and Roger R. S. 1977, Science, 195, 932-933

Baan W. A. 1999, Radio Sci. Bull., 289, 13-19

Clarke A. C. 1961, Harper's Mag., Dec. pp 56-62

Crane P. C. 1985, NRAO News, 24, 13

Dellinger J. H. 1961, URSI Info. Bull., 128, 78-79

Delogne P and Bellanger M. 1999, Radio Sci. Bull., 289, 23-28

Delogne P and van Himbeeck C. 1995, Radio. Sci. Bull., 275, 23-29 
Findlay J. W. 1988, URSI Info. Bull., 246, 14-19

Finney J. 1959, New York Times, CIX (Oct. 17), 47

Horner F. 1971, URSI Info. Bull., 181, 9-22

Horner F. 1980, URSI Info. Bull., 212, 14-16

Kellerman K. I. 1997, Sky Telesc. 93(2), 26-33

Lear J. 1959, Sat. Rev., 42 (Oct 3), 47-49

Lilley A. E. 1961, Astron. J., 66, 116-118

Ponsonby J. 1991, J. Navig., 44, 392-398

Ponsonby J. 1996, Nature, 381, 550

Robinson B. J. and Whiteoak J. 1979, Proc. Astron. Soc. Aust., 3, 396-400

Smith-Rose R. L. 1960, URSI Info. Bull., 123, 130-131

Smith-Rose RL. 1961, URSI Info. Bull., 128, 76-80

Sullivan W. 1959, New York Times, CIX (Sept. 20), 27

Westerhout G. 1979, Trans. IAU XVII(B), 245-247

Isn't a window overlooking the universe worth $\$ 100,000,000$ to the people? (That's what the requested radio astronomy channels might be worth in a TV auction.)

... If science doesn't get the right to use these radio channels for the future benefit of all the people, the channels will be grabbed up in time if not immeditately by the military and by whichever of the fiercely competing commercial interest prove able to pay the highest price.

J. Lear

Saturday Review, October 3, 1959, vol. 42, pp.47-49. 